\title{
NONALCOHOLIC FATTY LIVER DISEASE IN PATIENTS WITH CORONARY DISEASE FROM A BRAZIL NORTHEAST AREA
}

\author{
Consuêlo Padilha VILAR ${ }^{1,2}$, Helma Pinchemel COTRIM1', Gesira Soares Assis FLORENTIN01,2, \\ Gerson BRAGAGNOLI'², Paulo Adriano SCHWINGEL ${ }^{1}$ and Cibelle Padilha Vilar BARRETO²
}

\begin{abstract}
Background - Nonalcoholic fatty liver disease (NAFLD) is the most frequent chronic liver injury around the world. It is associated with metabolic syndrome and cardiovascular diseases. Objective - To evaluate the frequency and relevance of NAFLD in patients with coronary artery disease (CAD). Methods - Patients from a Brazil Northeast area, who underwent elective coronary angiography (CAG) from 2009 to 2010 were included. All of them had suspicion of CAD. Criteria to CAD: presence of obstructive lesions in the epicardial coronary arteries, or in their major branches. NAFLD criteria: presence of hepatic steatosis on ultrasound; exclusion of other liver diseases; ethanol intake $\leq 20 \mathrm{~g} /$ day. Statistics analysis included Independent $t$-test, Mann-Whitney and Pearson's chi-squared test. Multivariate regression analysis measured the relationship between the risk factors and the concomitant presence of CAD and NAFLD. Results - A total of 244 patients were evaluated: $63.5 \%$ had CAD and $42.2 \%$ had NAFLD. NAFLD was observed in $43.9 \%$ of the CAD patients. The regression analysis showed that the relationship between CAD and NAFLD was positively correlated with HOMA-IR $\geq 3.0$ or insulin resistance and overweight/obesity. Conclusion - NAFLD was frequent among CAD patients; insulin resistance and overweight/obesity were the most relevant risk factors related to the association NAFLD and CAD. The results suggest that patients with CAD should be evaluated for NAFLD.
\end{abstract}

HEADINGS - Fatty liver. Coronary artery disease. Cardiovascular diseases. Coronary angiography.

\section{INTRODUCTION}

Nonalcoholic fatty liver disease (NAFLD) in general is an asymptomatic and under-diagnosed condition in patients with cardiovascular disease (CVD). Some parameters such as the presence of diabetes mellitus (DM), overweight, obesity, insulin resistance (IR), and liver enzyme abnormalities may suggest the existence of NAFLD ${ }^{(12,22,24)}$. Coronary artery disease (CAD) and they have been associated with the severity, progression and mortality in patients with NAFLD. Some studies have shown histological changes of NAFLD in association with $\operatorname{CVD}^{(7,26)}$ and the relevance of the relationship between NAFLD and $\mathrm{CAD}^{(1,4,5)}$. NAFLD also likely represents an independent risk factor for CAD and this is one of the most important causes of morbidity and mortality among these patients ${ }^{(6,14,27)}$.

The influence of ethnicity has been discussed in patients with NAFLD ${ }^{(8,10)}$. The prevalence of NAFLD is more elevated in Hispanics than in whites, and African Americans ranking as the ethnic group with the least prevalence of NAFLD ${ }^{(9)}$.

The present study evaluated the frequency and relevance of NAFLD in patients with CAD from a Brazil Northeast area.

\section{METHODS}

\section{Study design and population selection}

From April 2009 to September 2010, patients who underwent elective coronary angiography (CAG) were included on this study. All of them came from a Brazil Northeast area. This population is composed of descends of Amerindians, Africans and Europeans.

Coronary angiography was performed in individuals under clinical investigation of CAD for stable angina pectoris, chest pain management or prognostic evaluation after acute myocardial infarction. All of them were previous evaluated at a public Cardiology Clinic, a reference center of cardiovascular diseases.

The exclusion criteria were patients, who presented $\mathrm{B}$ and $\mathrm{C}$ virus infection; hemochromatosis; autoimmune hepatitis; alcohol intake more than 20 grams of alcohol per day; CAG' performed for other reasons than CAD; drugs use such as glucocorticoids, estrogens, amiodarone, carbamazepine, tamoxifen or other agents considered risk factor to NAFLD.

Declared conflict of interest of all authors: none

Disclosure of funding: Centro Hospitalar João XXIII, Campina Grande, PB

${ }^{1}$ Programa de Pós-graduação em Medicina e Saúde (PPgMS), Faculdade de Medicina, Universidade Federal da Bahia (UFBA), Salvador, BA; ${ }^{2}$ Hospital Universitário Alcides Carneiro, Escola de Medicina, Universidade Federal de Campina Grande (UFCG), Campina Grande, PB. Brazil.

Correspondence: Prof. ${ }^{a}$ Helma Pinchemel Cotrim. Programa de Pós-graduação em Medicina e Saúde - PPGMS, Complexo Hospitalar Universitário Professor Edgard Santos, Rua Augusto Viana, s/n, $5^{\circ}$ andar, Canela - CEP 40110-060 - Salvador, BA, Brasil. E-mail: hpcotrim@ufba.br 
The Ethics Committee on Human Research of Hospital Universitário Alcides Carneiro from Universidade Federal de Campina Grande, Brazil, approved the study. It was conducted according to the principles outlined in the Declaration of Helsinki (1964, revised 2008).

\section{Patients' evaluation}

All patients answered a questionnaire, underwent physical examination and performed laboratory analysis and abdominal ultrasound (AUS).

The study parameters included gender, age, anthropometric measures, blood pressure levels, CAG indications, history of type 2 diabetes, arterial hypertension, dyslipidemia, acute myocardial infarction, alcohol intake, smoking habits and use of medications (including anti-diabetic, lipid-lowering, antihypertensive and hepatotoxic drugs: glucocorticoids, estrogens, amiodarone, carbamazepine, tamoxifen, and nonsteroidal anti-inflammatory).

Laboratory exams included HBsAg, anti-HCV, auto-antibodies (antinuclear, anti-smooth muscle, anti-mitochondria), total cholesterol (TC), high-density lipoprotein (HDL) cholesterol, low-density lipoprotein (LDL) cholesterol, triglycerides (TG), glucose, insulin, proteins, ferritin, transferrin saturation index, alanine aminotransferase (ALT), aspartate aminotransferase (AST), gamma-glutamyltransferase (GGT), and alkaline phosphatase.

\section{Measurements}

Anthropometric measurements were evaluated according to the World Health Organization guidelines ${ }^{(15,28)}$. Hypertension was diagnosed based on the VI Brazilian Guidelines on Hypertension $^{(23)}$. DM was defined in accordance with the World Health Organization guidelines ${ }^{(3)}$. Metabolic syndrome was defined according to the National Cholesterol Education Program Adult Treatment Panel III report ${ }^{(18)}$. HOMA-IR $\geq 3.0$ was considered insulin resistance ${ }^{(13,16)}$.

Consumption of at least one cigarette a day in a period not less than 6 months defined regular smoking and former smokers, were those who smoked regularly up to 6 months before the examination ${ }^{(30)}$. A practitioner conducted face-toface interviews to determine daily alcohol intake, smoking habits and medication consumption.

All patients included in the study had selective left and right coronary angiography with the Judkins technique using a Pollux 100KW device (X-PRO Sistemas Ltda., Belo Horizonte, Minas Gerais, Brazil). The CAG were evaluated and recorded by at least two experienced cardiologists who had no information about the study.

The diagnosis of fatty liver was based on abdominal ultrasonography with a $3.5 \mathrm{MHz}$ transducer using a Nemio 17 ultrasound machine (Toshiba Medical Systems Corporation, Otawara, Tochigi, Japan). The same experienced sonographer, who was not informed of the clinical history and CAG results, performed the abdominal ultrasound. Hepatic steatosis was diagnosed according to previous criteria ${ }^{(17,19)}$.

CAD criteria on coronary angiography: stenotic lesion in the epicardial coronary arteries or their major branches.
NAFLD criteria: presence of hepatic steatosis on ultrasound; exclusion of other liver diseases; ethanol intake $\leq 20 \mathrm{~g} /$ day.

\section{Statistical analysis}

Statistical analysis included the independent $t$ test and Mann-Whitney test for analysis of continuous variables, as appropriate. Categorical data were analyzed using Pearson's chi-square test. Multivariate regression analysis has measured the strength of the relationship between risk factors and the concomitant presence of CAD and NAFLD. Variables with $P$-value $\leq 0.15$ in the univariate analysis were selected as the independent variables for the multivariate study. A selection process "stepwise" was applied to obtain a reduced model. All continuous variables were entered into the logistic regression model as continuous variables; they weren't converted into categorical data. Concomitant CAD and NAFLD was selected as dependent variable. All statistical methods were two-tailed, $P$ values were calculated and the significance level was set to less than 0.05 .

\section{RESULTS}

Two hundred forty four patients were included. The clinical characteristics of the sample are in Table 1. CAG found 155 patients $(63.5 \%)$ with $\mathrm{CAD}([95 \% \mathrm{CI}]: 57.1-69.6 \%)$. The prevalence of risk factors, such as male gender, type 2 diabetes and smoking, were significantly higher $(P<0.05)$ in these patients than in the group without a CAD diagnosis (Table 2).

One hundred three $(42.2 \%)$ patients had NAFLD (95\%CI: $35.9-48.7 \%$ ), and it was strongly associated with central obesity, diabetes and insulin resistance (IR), and significantly related to higher body mass index values, neck and waist circumferences (Table 3 ). The association of NAFLD with metabolic syndrome $(P=0.024)$, lower levels of HDL-cholesterol $(P=0.043)$, higher levels of TG $(P=0.005)$, high levels of ALT $(P=0.003)$, and ferritin $(P=0.032)$ were significant.

The frequency of NAFLD in patients with a CAD was $43.9 \%$ (68/155). In univariate analysis (Table 4) several factors were statistically significant for the association between NAFLD and CAD including central obesity, neck circumference, ferritin, overweight/obesity, and HOMA-IR $\geq 3.0(P<0.001)$ Multivariate regression analysis was performed to measure the strength of the relationship between risk factors and the concomitant presence of CAD and NAFLD compared to CAD presence only. For the multivariate study, it was selected variables with $P<0.15$ in the univarieate analysis (Table 4). The variables age, DM, neck circumference, central obesity, overweight/obesity, fasting insulin, $\mathrm{HOMA} \geq 3.0$, TG, HDL-cholesterol, and ferritin entered in the initial model. With these variables it was adjusted a multivariate logistic regression model. The model selected age, diabetes, central obesity, neck circumference, overweight/obesity, fasting insulin, HOMA $\geq 3.0$, HDL-cholesterol, TG, and ferritin. A selection process "stepwise" was applied to obtain a reduced model. The adjusted model was given by HOMA $\geq 3.0$ and 
TABLE 1 . Clinical and laboratory characteristics of patients undergoing coronary angiography

\begin{tabular}{|c|c|}
\hline Variables & All patients $(n=244)$ \\
\hline Hypertension, n (\%) & $203(83.2)$ \\
\hline Fast insulin $(\mu \mathrm{UI} / \mathrm{mL})$ & $9.1 \pm 8.5$ \\
\hline HOMA-IR & $2.8 \pm 3.1$ \\
\hline HOMA $\geq 3.0, \mathrm{n}(\%)$ & $68(27.9)$ \\
\hline Central obesity, n (\%) & $147(60.2)$ \\
\hline Overweight/obesity, n (\%) & $182(74.6)$ \\
\hline Neck circumference (cm) & $38.2 \pm 3.6$ \\
\hline Metabolic syndrome, n (\%) & $168(68.9)$ \\
\hline Smoking, n (\%) & $141(57.8)$ \\
\hline Use of statin therapy, $\mathrm{n}(\%)$ & $112(45.9)$ \\
\hline $\operatorname{AST}(\mathrm{U} / \mathrm{L})$ & $24.4 \pm 13.5$ \\
\hline ALT (U/L) & $30.8 \pm 20.0$ \\
\hline Ferritin $(\mathrm{ng} / \mathrm{mL})$ & $178.4 \pm 169.3$ \\
\hline GGT (U/L) & $45.1 \pm 53.2$ \\
\hline CAD, n (\%) & $155(63.5)$ \\
\hline NAFLD, n (\%) & $103(42.2)$ \\
\hline
\end{tabular}

Continuous variables: mean \pm SD; categorical variables: $\mathrm{n}(\%)$; HOMA-IR: homeostasis model assessment-insulin resistance index; BMI: body mass index; TC: total cholesterol; HDL: high-density lipoprotein; LDL: low-density lipoprotein; AST: aspartate aminotransferase; ALT: alanine aminotransferase; GGT: gamma-glutamyltransferase; CAD: coronary artery disease; NAFLD: nonalcoholic fatty liver disease.

TABLE 2. Clinical and laboratory data of patients undergoing coronary angiography, according to the diagnosis of coronary artery disease

\begin{tabular}{|c|c|c|c|c|}
\hline \multirow[b]{2}{*}{ Variables } & \multicolumn{3}{|c|}{ Coronary artery disease } & \multirow[b]{2}{*}{$P$ Value } \\
\hline & $\begin{array}{c}\text { Total } \\
(\mathrm{n}=244)\end{array}$ & $\begin{array}{c}\text { Present } \\
(155)\end{array}$ & $\begin{array}{c}\text { Absent } \\
(89)\end{array}$ & \\
\hline Age (years) & $61.5 \pm 9.3$ & $62.3 \pm 9.3$ & $60.0 \pm 9.0$ & 0.067 \\
\hline Male, n (\%) & $126(51.6)$ & $99(63.9)$ & $27(30.3)$ & $<0.001$ \\
\hline Hypertension, n (\%) & $203(83.2)$ & $126(81.3)$ & $77(86.5)$ & 0.293 \\
\hline Diabetes Mellitus, n (\%) & $66(27.0)$ & $51(32.9)$ & $15(16.9)$ & 0.007 \\
\hline Smoking, n (\%) & $141(57.8)$ & $97(62.6)$ & $44(49.4)$ & 0.045 \\
\hline Waist circumference $(\mathrm{cm})$ & $99 \pm 11$ & $99 \pm 10$ & $100 \pm 13$ & 0.567 \\
\hline Central obesity, n (\%) & $147(60.2)$ & $85(54.8)$ & $62(69.7)$ & 0.023 \\
\hline Neck circumference $(\mathrm{cm})$ & $38 \pm 4$ & $39 \pm 3$ & $37 \pm 3$ & 0.015 \\
\hline Body mass index $\left(\mathrm{kg} / \mathrm{m}^{2}\right)$ & $28.0 \pm 4.5$ & $27.6 \pm 4.2$ & $28.7 \pm 5.0$ & 0.084 \\
\hline Overweight/obesity, n (\%) & $182(74.6)$ & $114(73.5)$ & $68(76.4)$ & 0.622 \\
\hline Metabolic syndrome, n (\%) & $168(68.9)$ & $104(67.1)$ & $64(71.9)$ & 0.434 \\
\hline Fasting insulin $(\mu \mathrm{UI} / \mathrm{mL})$ & $9.1 \pm 8.6$ & $10.0 \pm 10.0$ & $7.5 \pm 4.5$ & $0.008^{(*)}$ \\
\hline HOMA-IR index & $2.8 \pm 3.1$ & $3.0 \pm 3.5$ & $2.3 \pm 2.4$ & $0.098^{(*)}$ \\
\hline HOMA-IR $\geq 3.0, \mathrm{n}(\%)$ & $68(27.9)$ & $49(32.9)$ & $19(22.6)$ & 0.098 \\
\hline Total cholesterol (mg/dL) & $192.9 \pm 54.2$ & $185.1 \pm 54.5$ & $206.4 \pm 51.2$ & 0.003 \\
\hline HDL cholesterol (mg/dL) & $41.2 \pm 9.7$ & $38.9 \pm 8.4$ & $45.3 \pm 10.5$ & $<0.001$ \\
\hline LDL cholesterol (mg/dL) & $112.6 \pm 42.5$ & $107.7 \pm 42.4$ & $120.6 \pm 41.6$ & 0.026 \\
\hline Triglycerides $(\mathrm{mg} / \mathrm{dL})$ & $200.2 \pm 143.2$ & $203.9 \pm 159.6$ & $193.8 \pm 109.4$ & 0.596 \\
\hline $\operatorname{AST}(\mathrm{U} / \mathrm{L})$ & $24.4 \pm 13.5$ & $24.3 \pm 12.8$ & $24.7 \pm 14.8$ & 0.847 \\
\hline $\operatorname{ALT}(\mathrm{U} / \mathrm{L})$ & $30.8 \pm 20.0$ & $31.8 \pm 19.7$ & $29.2 \pm 20.4$ & 0.326 \\
\hline Ferritin $(\mathrm{ng} / \mathrm{mL})$ & $178.4 \pm 169.3$ & $205.6 \pm 194.2$ & $131.1 \pm 98.7$ & $<0.001^{(*)}$ \\
\hline GGT (U/L) & $45.0 \pm 53.2$ & $49.6 \pm 61.6$ & $37.0 \pm 32.2$ & $0.074^{(*)}$ \\
\hline Use of statin therapy, n (\%) & $112(45.9)$ & $89(57.4)$ & $23(25.8)$ & $<0.001$ \\
\hline NAFLD, $\mathrm{n}(\%)$ & $103(42.2)$ & $68(43.9)$ & $35(39.3)$ & 0.489 \\
\hline
\end{tabular}

Continuous variables: mean \pm SD; categorical variables: $\mathrm{n}(\%)$; (*) Mann-Whitney test; HOMA-IR: homeostasis model assessment-insulin resistance index; HDL: high-density lipoprotein; LDL: low-density lipoprotein; AST: aspartate aminotransferase; ALT: alanine aminotransferase; GGT: gamma-glutamyltransferase; NAFLD: nonalcoholic fatty liver disease. 
TABLE 3. Clinical and laboratory data of patients undergoing coronary angiography, according to the diagnosis of nonalcoholic liver disease

\begin{tabular}{|c|c|c|c|c|}
\hline \multirow{2}{*}{ Variables } & \multirow{2}{*}{ Total $(n=244)$} & \multicolumn{2}{|c|}{ Nonalcoholic liver disease } & \multirow{2}{*}{$P$ value } \\
\hline & & Present $(n=103)$ & Absent $(n=141)$ & \\
\hline Age (years) & $61.5 \pm 9.3$ & $60.7 \pm 9.0$ & $62.0 \pm 9.5$ & 0.259 \\
\hline Male, n (\%) & $126(51.6)$ & $52(50.5)$ & $74(52.5)$ & 0.758 \\
\hline Hypertension, n (\%) & $203(83.2)$ & $84(81.6)$ & $119(84.4)$ & 0.557 \\
\hline Diabetes Mellitus, n (\%) & $66(27.0)$ & $38(36.9)$ & $28(19.9)$ & 0.003 \\
\hline Smoking, n (\%) & $141(57.8)$ & $54(52.4)$ & $87(61.7)$ & 0.147 \\
\hline Waist circumference $(\mathrm{cm})$ & $99 \pm 11$ & $104 \pm 9$ & $95 \pm 11$ & $<0.001$ \\
\hline Central obesity, n (\%) & $147(60.2)$ & $75(72.8)$ & $72(51.1)$ & 0.001 \\
\hline Neck circumference $(\mathrm{cm})$ & $38 \pm 4$ & $39 \pm 3$ & $37 \pm 3$ & $<0.001$ \\
\hline Body mass index $\left(\mathrm{kg} / \mathrm{m}^{2}\right)$ & $28.0 \pm 4.5$ & $30.2 \pm 4.1$ & $26.4 \pm 4.2$ & $<0.001$ \\
\hline Overweight/obesity, n (\%) & $182(74.6)$ & $95(92.2)$ & $87(47.8)$ & $<0.001$ \\
\hline Metabolic syndrome, n (\%) & $168(68.9)$ & $79(76.7)$ & $89(63.1)$ & 0.024 \\
\hline Fasting insulin $(\mu \mathrm{UI} / \mathrm{ml})$ & $9.1 \pm 8.6$ & $11.4 \pm 8.9$ & $7.4 \pm 7.9$ & $<0.001^{(*)}$ \\
\hline HOMA-IR index & $2.8 \pm 3.1$ & $3.6 \pm 3.0$ & $2.2 \pm 3.1$ & $0.001^{(*)}$ \\
\hline HOMA-IR $\geq 3.0, \mathrm{n}(\%)$ & $68(27.9)$ & $45(45.5)$ & $23(17.2)$ & $<0.001$ \\
\hline Total Cholesterol (mg/dL) & $192.9 \pm 54.2$ & $193.6 \pm 52.7$ & $192.4 \pm 55.4$ & 0.864 \\
\hline HDL cholesterol (mg/dL) & $41.2 \pm 9.7$ & $39.8 \pm 9.1$ & $42.3 \pm 10.0$ & 0.043 \\
\hline LDL cholesterol (mg/dL) & $112.6 \pm 42.5$ & $108.8 \pm 39.3$ & $115.1 \pm 44.5$ & 0.268 \\
\hline Triglycerides (mg/dL) & $200.2 \pm 142.2$ & $232.3 \pm 172.4$ & $176.8 \pm 112.4$ & 0.005 \\
\hline AST (U/L) & $24.5 \pm 13.6$ & $25.7 \pm 13.9$ & $23.5 \pm 13.2$ & 0.224 \\
\hline $\operatorname{ALT}(\mathrm{U} / \mathrm{L})$ & $30.8 \pm 20.0$ & $35.3 \pm 21.9$ & $27.6 \pm 17.9$ & 0.003 \\
\hline Ferritin $(\mathrm{ng} / \mathrm{mL})$ & $178.4 \pm 169.3$ & $205.4 \pm 191.0$ & $158.4 \pm 149.0$ & $0.032^{(*)}$ \\
\hline GGT (U/L) & $45.0 \pm 53.2$ & $47.2 \pm 36.1$ & $43.5 \pm 62.8$ & $0.586^{(*)}$ \\
\hline Use of statin therapy, $\mathrm{n}(\%)$ & $112(45.9)$ & $44(42.7)$ & $68(48.2)$ & 0.394 \\
\hline $\mathrm{CAD}, \mathrm{n}(\%)$ & $155(63.5)$ & $68(66.0)$ & $87(61.7)$ & 0.489 \\
\hline
\end{tabular}

Continuous variables: mean $\pm \mathrm{SD}$; categorical variables: $\mathrm{n}(\%) ;(*)$ Mann-Whitney test; HOMA-IR: homeostasis model assessment-insulin resistance index; HDL: high-density lipoprotein; LDL: low-density lipoprotein; AST: aspartate aminotransferase; ALT; alanine aminotransferase; GGT: gamma-glutamyltransferase; CAD: coronary artery disease.

TABLE 4. Risk factors related to NAFLD in patients with CAD

\begin{tabular}{|c|c|c|c|c|}
\hline \multirow{2}{*}{ Variables } & \multirow{2}{*}{ Total $(\mathrm{n}=155)$} & \multicolumn{2}{|c|}{ NAFLD } & \multirow{2}{*}{$P$ Value } \\
\hline & & Present $(n=68)$ & Absent $(n=87)$ & \\
\hline Age (years) & $62.3 \pm 9.3$ & $60.7 \pm 9.3$ & $63.6 \pm 9.2$ & 0.053 \\
\hline Gerder: Male, n (\%) & 99 (63.9) & $41(60.3)$ & $58(66.7)$ & \multirow{2}{*}{0.412} \\
\hline Gerder: Female, n (\%) & $56(36.1)$ & $27(39.7)$ & $29(33.3)$ & \\
\hline Hypertension, n (\%) & $126(81.3)$ & $53(77.9)$ & $73(83.9)$ & 0.344 \\
\hline Diabetes Mellitus, n (\%) & $51(32.9)$ & $27(39.7)$ & $24(27.6)$ & 0.111 \\
\hline Smoking, n (\%) & $97(62.6)$ & $40(58.8)$ & $57(65.5)$ & 0.393 \\
\hline Central obesity, n (\%) & $85(54.8)$ & $45(66.2)$ & $40(46.0)$ & 0.012 \\
\hline Neck circumference $(\mathrm{cm})$ & $38.6 \pm 3.5$ & $39.8 \pm 3.2$ & $37.7 \pm 3.5$ & $<0.001$ \\
\hline Overweight/obesity, n (\%) & $114(73.5)$ & $63(92.6)$ & $51(58.6)$ & $<0.001$ \\
\hline Metabolic syndrome, n (\%) & $104(67.1)$ & $49(72.1)$ & $55(63.2)$ & 0.245 \\
\hline Use of statin therapy, $\mathrm{n}(\%)$ & $89(57.4)$ & $36(52.9)$ & $53(60.9)$ & 0.319 \\
\hline Fasting insulin $(\mu \mathrm{UI} / \mathrm{mL})$ & $10.0 \pm 10.0$ & $12.3 \pm 10.1$ & $8.2 \pm 9.7$ & $0.014^{(*)}$ \\
\hline HOMA-IR $\geq 3.0, \mathrm{n}(\%)$ & $49(32.9)$ & $34(50.0)$ & $16(19.3)$ & $<0.001^{(*)}$ \\
\hline $\mathrm{TC}(\mathrm{mg} / \mathrm{dL})$ & $185.1 \pm 54.5$ & $186.2 \pm 46.8$ & $184.3 \pm 60.1$ & 0.882 \\
\hline HDL-cholesterol (mg/dL) & $39.8 \pm 8.4$ & $37.7 \pm 7.6$ & $39.9 \pm 8.9$ & 0.110 \\
\hline LDL-cholesterol (mg/dL) & $107.7 \pm 42.4$ & $106.5 \pm 36.8$ & $108.5 \pm 46.4$ & 0.770 \\
\hline Triglycerides (mg/dL) & $203.9 \pm 159.6$ & $233.6 \pm 187.3$ & $180.7 \pm 130.7$ & 0.040 \\
\hline AST (U/L) & $24.3 \pm 12.8$ & $24.6 \pm 10.3$ & $24.1 \pm 14.6$ & 0.800 \\
\hline $\operatorname{ALT}(\mathrm{U} / \mathrm{L})$ & $31.8 \pm 19.7$ & $34.2 \pm 20.3$ & $29.9 \pm 19.2$ & 0.173 \\
\hline Ferritin $(\mathrm{ng} / \mathrm{mL})$ & $205.6 \pm 194.2$ & $231.5 \pm 214.9$ & $185.2 \pm 174.7$ & $0.041^{(*)}$ \\
\hline GGT (U/L) & $49.5 \pm 61.6$ & $47.2 \pm 32.8$ & $51.4 \pm 77.1$ & $0.668^{(*)}$ \\
\hline
\end{tabular}

Continuous variables: mean \pm SD; categorical variables: $\mathrm{n}(\%)$; (*) Mann-Whitney test; NAFLD: nonalcoholic fatty liver disease; CAD: coronary artery disease; HOMA-IR: homeostasis model assessment-insulin resistance index; TC: Total cholesterol; HDL: high-density lipoprotein; LDL: low-density lipoprotein; AST: aspartate aminotransferase; ALT: alanine aminotransferase; GGT: gamma-glutamyltransferase. 
overweight or obesity. The result of regression analysis showed that the possibility of concomitant occurrence of CAD and NAFLD was positively correlated with these variables (Table 5). The positive predictive value found for HOMA $\geq 3.0$ was $67.3 \%$, while the negative predictive value was $67 \%$. In relation to overweight or obesity, these values were $55.2 \%$ and $87.8 \%$, respectively.

TABLE 5. Multivariate regression analysis for predictors of NAFLD and CAD association

\begin{tabular}{lccc}
\hline Variables $^{(*)}$ & Odds ratio & $95 \%$ CI & $\boldsymbol{P}$ value \\
\hline overweight/obesity $^{*}$ & 6.46 & $(2.29 ; 18.17)$ & $<0.001$ \\
HOMA-IR $\geq 3.0$ & 3.00 & $(1.40 ; 6.47)$ & 0.005 \\
\hline
\end{tabular}

(*)Variables entered in the analysis: age, diabetes, central obesity, neck circumference, overweight/obesity, fasting insulin, HOMA $\geq 3.0$, HDL-cholesterol, Triglycerides, and ferritin; NAFLD: nonalcoholic fatty liver disease; CAD: coronary artery disease; CI: confidence interval; HOMA-IR: homeostasis model assessment-insulin resistance index.

\section{DISCUSSION}

Some studies have evaluated the association between NAFLD and CAD diagnosed by coronary angiography $(1,4,5,25,29)$ a gold standard method for diagnosis of coronary disease. However, most of them have evaluated the risk factors, and its relationship with the presence of CAD or NAFLD alone and the majority of the studies come from Asia.

The present study included a large series of patients submitted to coronary angiography, who come from an area of Northeast of Brazil which population has a low economic status and several ethnic descended, like Amerindians, Africans and Europeans.

These factors are relevant. Race and ethnicity can be predictive factors of liver diseases complications and response to treatment in patients with chronic liver disease. These ethnic differences should influence the prevalence and profile of NAFLD in South America and studies from some countries have shown the relevance of this liver disease in this continent ${ }^{(20,21)}$.

The risk factors related to the presence of CAD in these Brazilian patients were male gender, smoking, type 2 diabetes, lower levels of HDL-cholesterol and a higher frequency of use of lipid-lowering drugs. NAFLD was associated with $\mathrm{DM}$, insulin resistance, BMI, higher levels of triglycerides and waist circumference, lower HDL-cholesterol, obesity, and metabolic syndrome. Similar results were found in other studies regarding CAD and gender ${ }^{(1,25,29)}$, smoking, $\mathrm{DM}^{(1)}$, lower levels of HDL-cholesterol ${ }^{(1,29)}$, and a higher frequency of use of lipid-lowering drugs ${ }^{(1)}$ and NAFLD association with $\mathrm{DM}^{(25,29)}$, BMI, higher levels of triglycerides and waist circumference, lower HDL-cholesterol levels ${ }^{(4,25,29)}$, obesity, and metabolic syndrome ${ }^{(25)}$.

This investigation did not observe association between NAFLD and age, arterial hypertension, gender, and CAD. These results are distinct from other studies especially regarding the absence of association between NAFLD and $\mathrm{CAD}^{(1,4,5,25,29)}$. The hypothesis for these findings are the different population, who was evaluated; the criteria of CAD diagnose; and the patients' precedence. The majority of these individuals came from out clinics to perform elective coronary angiography with suspicion of CAD. The similar studies included patients with metabolic syndrome only ${ }^{(4)}$, admitted with acute coronary syndrome and $\mathrm{AMI}^{(1,29)}$ and hospitalized patients with $\mathrm{CAD}^{(25)}$. These cases, in general, have more severe CAD disease.

The criteria for CAD used here was different from other studies, because any obstructive lesion in the epicardial coronary arteries or in their major branches were considered. This approach can help early diagnosis of CAD in patients with NAFLD. Taking into account that coronary occlusion and myocardial ischemia may frequently be due to mild or moderate lesion, the identification of such levels of obstruction in patients with NAFLD might be important for the risk stratification and therapeutic orientation. It could also help to reduce morbidity and mortality of these patients. However, others considered the stenosis of at least $50 \%$ in at least one major coronary artery to CAD diagnosis ${ }^{(5,25,29)}$, or stenosis of at least $50 \%$ in epicardial arteries or their major branches ${ }^{(1)}$, and two studies evaluated the association between NAFLD and CAD severity ${ }^{(4,25)}$. In this sense, significant stenosis was defined as $70 \%$ or greater reduction in luminal diameter in any view compared with the nearest normal segment.

The patients' background and ethnicity should also be considered in the discussion. This study included patients with several ethnic descended who come from South America and the majority of others studies came from Asia. There they have others epidemiological factors, ethnicity and behaviors, that could have influenced the results. Asians, even those living in the West, seem to be more at risk for NAFLD than their Caucasian and African American counterparts. In addition, they develop NAFLD at a younger age, and NAFLD patients are more likely to be male ${ }^{(2)}$. These characteristics could contribute to the NAFLD and CAD association.

Therefore, this study made possible to inform the scientific community, results observed in our population which has socioeconomic, ethnic and behavioral characteristics different from other populations previously studied. On the other hand, our results agree with the study published by Feitosa et al. (11), which evaluated 2,756 European-American. In their study, no association was observed between fatty liver diagnosed by computed tomography and coronary heart disease.

In conclusion, this is the first study that involved patients from a Brazil Northeast area and that showed the relevance of NAFLD in patients with CAD. The regression analysis showed that insulin resistance, overweight or obesity are the most relevant risk factors for the possibility of concomitant occurrence of CAD and NAFLD in these patients, and the results suggested that NAFLD should be investigated in CAD patients with these characteristics, in order to reduce morbidity and mortality.

\section{ACKNOWLEDGMENTS}

The authors would like to thank Hospital Universitário Alcides Carneiro (HUAC) from Universidade Federal de Campina Grande (UFCG) and the Centro Hospitalar João XXIII for financial support. 


\section{Authors' contributions}

The authors Vilar CP and Cotrim HP participated in the conception and design of the research, obtaining finance, collection, analysis and data interpretation, writing of the manuscript, and revising it critically for intellectual content; Florentino GSA and Barreto CPV participated in the collection and interpretation of data; Bragagnoli $\mathrm{G}$ and Schwingel PA participated in the analysis and interpretation of data, and statistical analysis.

Vilar CP, Cotrim HP, Florentino GSA, Bragagnoli G, Schwingel PA, Barreto CPV. Doença hepática gordurosa não alcoólica em pacientes com doença coronariana de uma área do Nordeste do Brasil. Arq Gastroenterol. 2015,52(2):111-6.

RESUMO - Contexto - Doença hepática gordurosa não alcoólica (DHGNA) é uma das mais frequentes hepatopatias crônicas da atualidade. Associa-se à síndrome metabólica e doenças cardiovasculares. Objetivo - Avaliar a frequência e relevância da DHGNA em pacientes com doença arterial coronariana (DAC). Métodos - Foram avaliados pacientes de uma área do Nordeste de Brasil, submetidos à angiografia coronariana, com suspeita de DAC, entre 2009-2010. Critérios para DAC: presença de lesões obstrutivas em artérias coronárias epicárdicas ou seus principais ramos. Critérios para DHGNA: esteatose hepática na ultrassonografia; exclusão de outras doenças hepáticas; ingestão de etanol $\leq 20 \mathrm{~g} /$ dia. Análise estatística incluiu os testes $t$, Mann-Whitney e qui-quadrado de Pearson. Análise de regressão multivariada mediu a força da correlação entre fatores de risco e concomitância de DAC e DHGNA. Resultados - Foram avaliados 244 pacientes submetidos à angiografia coronariana: 63,5\% apresentavam DAC e 42,2\% DHGNA. DHGNA foi observada em 43,9\% dos doentes com DAC. A análise de regressão mostrou que a possibilidade de ocorrência concomitante de DAC e DHGNA foi positivamente correlacionadas à resistência a insulina e ao sobrepeso/obesidade. Conclusão - DHGNA foi frequente entre os pacientes com DAC; resistência à insulina e sobrepeso/obesidade foram os mais relevantes fatores de risco relacionados à associação DHGNA e DAC. Os dados sugerem que pacientes com DAC devem ser avaliados para DHGNA.

DESCRITORES - Fígado gorduroso. Doença da artéria coronariana. Doenças cardiovasculares. Angiografia coronária.

\section{REFERENCES}

1. Açikel M, Sunay S, Koplay M, Gündoğdu F, Karakelleoğlu S. Evaluation of ultrasonographic fatty liver and severity of coronary atherosclerosis, and obesity in patients undergoing coronary angiography. Anadolu Kardiyol Derg. 2009;9(4):273-9.

2. Agrawal S, Duseja AK. Non-alcoholic Fatty Liver Disease: East Versus West. J Clin Exp Hepatol. 2012;2:122-34

3. Alberti KG,Zimmet PZ. Definition, diagnosis and classification of diabetes mellitus and its complications. Part 1: diagnosis and classification of diabetes mellitus provisional report of a WHO consultation. Diabet Med. 1998;15(7):539-53.

4. Alper AT, Hasdemir H, Sahin S, Onturk E, Akyol A, Nurkalem Z, et al. The relationship between nonalcoholic fatty liver disease and the severity of CAD in patients with metabolic syndrome. Turk Kardiyol Dern Ars. 2008;36(6):376-81.

5. Arslan U, Türkoğlu S, Balcioğlu S, Tavil Y, Karakan T, Cengel A. Association between nonalcoholic fatty liver disease and coronary artery disease. Coron Artery Dis 2007;18(6):433-6.

6. Ballestri S, Lonardo A, Bonapace S, Byrne CD, Loria P, Targher G. Risk of cardiovascular, cardiac and arrhythmic complications in patients with non-alcoholic fatty liver disease. World J Gastroenterol. 2014;20(7):1724-45.

7. Băloșeanu CL, Streba CT, Vere CC, Comănescu V, Rogoveanu I. Association between liver histology, carotid ultrasonography and retinal vascular changes in patients with nonalcoholic fatty liver disease (NAFLD). Rom J Morphol Embryol. 2012;53(3):609-14.

8. Bambha K, Belt P, Abraham M, Wilson LA, Pabst M, Ferrell L, et al. Nonalcoholic Steatohepatitis Clinical Research Network Research Group. Ethnicity and nonalcoholic fatty liver disease. Hepatology. 2012;55(3):769-80.

9. Browning JD, Szczepaniak LS, Dobbins R, Nuremberg P, Horton JD, Cohen JC, et al. Prevalence of hepatic steatosis in an urban population in the United States: impact of ethnicity. Hepatology. 2004;40(6):1387-95.

10. Chan WK, Bahar N, Razlan H, Vijayananthan A, Sithaneshwar P, Goh KL. Non-alcoholic fatty liver disease in a young multiracial Asian population: a worrying ethnic predilection in Malay and Indian males. Hepatol Int. 2014;8:121-7.

11. Feitosa MF, Reiner AP, Wojczynski MK, Graff M, North KE, Carr JJ, et al. Sex-influenced association of nonalcoholic fatty liver disease with coronary heart disease. Atherosclerosis. 2013;227(2):420-4.

12. Ferreira VS, Pernambuco RB, Lopes EP, Morais CN, Rodrigues MC, Arruda MJ, et al. Frequency and risk factors associated with non-alcoholic fatty liver disease in patients with type 2 diabetes mellitus. Arq Bras Endocrinol Metabol. 2010;54(4):362-8.

13. Guidorizzi de Siqueira AC, Cotrim HP, Rocha R, Carvalho FM, de Freitas LA, Barreto $\mathrm{D}$, et al. Non-alcoholic fatty liver disease and insulin resistance: importance of risk factors and histological spectrum. Eur J GastroenterolHepatol. 2005;17(8):837-41.

14. Hamaguchi M, Kojima T, Takeda N, Nagata C, Takeda J, Sarui H, et al. Nonalcoholic fatty liver disease is a novel predictor of cardiovascular disease. World J Gastroenterol. 2007;13(10): 1579-84.

15. Marfell-Jones M, Olds T, Stewart A, Carter L. International standards for anthropometric assessment. Potchefstroom, South Africa: International Society for the Advancement of Kinanthropometry. 2006:1-137.
16. Matthews DR, Hosker JP, Rudenski AS, Naylor BA, Treacher DF, Turner RC. Homeostasis model assessment: insulin resistance and beta-cell function from fasting plasma glucose and insulin concentrations in man. Diabetologia. 1985;2(22):3476-83.

17. Mehta SR, Thomas EL, Bell JD, Johnston DG, Taylor-Robinson SD. Non-invasive means of measuring hepatic fat content. World J Gastroenterol. 2008;14(22):3476-83.

18. National Cholesterol Education Program (NCEP), National Heart, Lung and Blood Institute, National Institutes of Health. Third Report of the National Cholesterol Education Program (NCEP) Expert Panel on Detection, Evaluation, and Treatment of High Blood Cholesterol in Adults (Adult Treatment Panel III): final report. Circulation. 2002;106(25):3143-421.

19. Pacifico L, Celestre M, Anania C, Paolantonio P, Chiesa C, Laghi A. MRI and ultrasound for hepatic fat quantification: relationships to clinical and metabolic characteristics of pediatric nonalcoholic fatty liver disease. Acta Paediatr. 2007;96(4):542-7.

20. Perez M, Gonzáles L, Olarte R, Rodriguez NI, Tabares M, Salazar JP, et al. Nonalcoholic fatty liver disease is associated with insulin resistance in a young Hispanic population. Prev Med. 2011;52(2):174-7.

21. Riquelme A, Arrese M, Soza A, Morales A, Baudrand R, Pérez-Ayuso RM, et al Non-alcoholic fatty liver disease and its association with obesity, insulin resistance and increased serum levels of C-reactive protein in Hispanics. Liver Int. 2009;29(1):82-8.

22. Salgado AL, Carvalho LD, Oliveira AC, Santos VN, Vieira JG, Parise ER. Insulin resistance index (HOMA-IR) in the differentiation of patients with non-alcoholic fatty liver disease and healthy individuals. Arq Gastroenterol. 2010;47(2):165-9.

23. Sociedade Brasileira de Cardiologia; Sociedade Brasileira de Hipertensão; Sociedade Brasileira de Nefrologia. [VI Brazilian Guidelines on Hypertension]. Arq Bras Cardiol. 2010;95(1 Suppl):1-51.

24. Souza MR, Diniz M.F, Medeiros-Filho JE, Araújo MS. Metabolic syndrome and risk factors for non-alcoholic fatty liver disease. Arq Gastroenterol. 2012;49(1):89-96.

25. Sun L, Lu SZ. Association between non-alcoholic fatty liver disease and CAD severity. Chin Med J (Engl). 2011;124(6):867-72.

26. Targher G, Bertolini L, Padovani R, Rodella S, Zoppini G, Zenari L, et al. Relations Between Carotid Artery Wall Thickness and Liver Histology in Subjects With Nonalcoholic Fatty Liver Disease. Diabetes Care. 2006;29(6):1325-30.

27. Treeprasertsuk S, Lopez;Jimenez F, Lindor KD. Nonalcoholic fatty liver disease and the coronary artery disease. Dig Dis Sci. 2011;56(1):35-45.

28. WHO Expert Committee on Physical Status. Physical Status: the use and interpretation of anthropometry. World Health Organ Tech Rep Ser. 1995;854:1-453.

29. Wong VW, Wong GL, Yip GW, Lo AO, Limquiaco J, Chu WC, et al. Coronary artery disease and cardiovascular outcomes in patients with non-alcoholic fatty liver disease. Gut. 2011;60(12):1721-7.

30. World Health Organization. Guidelines for the Conduct of tobacco-smoking among health professionals. Report WHO/SMO 84.1. Geneva: World Health Organization, 1984:1-19.

Received 10/10/2014 Accepted 20/10/2014 